\title{
KUALITAS PELAYANAN DALAM MENINGKATKAN LOYALITAS WISATAWAN PULAU TIDUNG KEPULAUAN SERIBU
}

\author{
Farida Farida', Annisa Retno Utami² \\ Fakultas Ekonomi dan Bisnis, Universitas Sahid \\ Jl. Soepomo No 84, Jakarta Selatan \\ Email Korespondensi: faridarustamuji2017@gmail.com
}

\begin{abstract}
ABSTRAK
Pulau Tidung menjadi salah satu destinasi yang diminati banyak pengunjung karena memiliki ciri khas dibandingkan dengan pulau-pulau lainnya yang ada di Kepulauan Seribu. Salah satu Pulau Tidung menjadi salah satu destinasi yang diminati banyak pengunjung yaitu adanya kualitas pelayanan yang diberikan yang dapat menimbulkan loyalitas dari wisatawan untuk datang kembali ke Pulau Tidung. Tujuan dari penelitian ini yaitu : (1) Untuk mengetahui kualitas pelayanan di Pulau Tidung dan (2) Untuk mengetahui Loyalitas wisatawan yang datang ke Pulau Tidung. Penelitian dilakukan dengan menyebar kuesioner terhadap 100 wisatawan yang telah berkunjung ke Pulau Tidung minimal sebanyak 2 kali. Metode analisis yang digunakan pada penelitian ini dengan analisis deskriptif. Dari hasil penelitian diperoleh skor tertinggi pada variabel kualitas pelayanan yaitu pada indikator pengetahuan petugas dalam memberikan informasi yang jelas kepada wistawan dan kelengkapan fasilitas permainan air di Pulau Tidung, sedangkan untuk variabel loyalitas wisatawan hasil tertinggi pada indikator kesediaan wistawan dalam berkunjung kembali dan untuk hasil terendah pada keinginan untuk tidak berpindah pada objek wisata lainnya.
\end{abstract}

Kata Kunci : Kualitas pelayanan, Loyalitas wisatawan, Pulau Tidung

\begin{abstract}
Tidung Island became one of the destinations that attracted many visitors because it has a distinctive character compared to other islands in the Thousand Islands. One of Tidung Island became one of the destinations that attracted many visitors that is the quality of services provided that can lead to loyalty from tourists to come back to Tidung Island. The purpose of this research are: (1) To know the quality of service in Tidung Island and (2) To know Loyalty of tourists who come to Tidung Island. The research was conducted by spreading questionnaires to 100 tourists who have visited Tidung Island at least 2 times. The method of analysis used in this study with descriptive analysis. From the research results obtained the highest score on the variable quality of service is the indicator of knowledge officers in providing clear information to the wistawan and completeness of water games facilities on the island Tidung, while for variable loyalty tourists the highest yield on indicators of willingness of tourists in return visit and for the lowest results on the desire to not move on other attractions.
\end{abstract}

Keywords : Service Quality, Loyalty of tourist, Tidung Island 


\section{PENDAHULUAN}

Pariwisata dianggap sebagai salah satu aset yang strategis dalam mendorong pembangunan pada wilayah-wilayah tertentu yang mempunyai potensi objek wisata. Dengan adanya pengembangan sektor pariwisata yang dilakukan dengan baik oleh pengelola swasta maupun pemerintah, dapat menarik wisatawan domestik maupun wisatawan asing untuk berkunjung. Menurut Undang-Undang Nomor 10 Tahun 2009 Tentang Kepariwisataan menyatakan bahwa Penyelenggaraan Kepariwisataan ditujukkan untuk meningkatkan pendapatan nasional, serta meningkatkan kesejahteraan dan kemakmuran rakyat, memperluas dan memeratakan kesempatan usaha dan lapangan kerja, mendorong pembangunan daerah, memperkenalkan dan mendayagunakan objek dan daya tarik wisata di Indonesia serta memupuk rasa cinta tanah air dan mempererat persahabatan antar bangsa. Dengan demikian pada tiap-tiap objek wisata diperlukan pengembangan dan peningkatan pengelolaan dalam sektor pariwisata.

Kepulauan Seribu merupakan wilayah Administratif DKI Jakarta yang terdiri dari pulau-pulau sebanyak 110 pulau. Adapun jumlah pengunjung ke wilayah Kepulauan Seribu dapat dilihat pada Tabel 1

Tabel 1 Jumlah Kunjungan Wisatawan di Kepulauan Seribu Jakarta Tahun 2013

\begin{tabular}{|l|l|c|c|c|}
\hline No & Nama Pulau & $\begin{array}{l}\text { Wisman } \\
\text { (Orang) }\end{array}$ & $\begin{array}{l}\text { Wisnus } \\
\text { (Orang) }\end{array}$ & Jumlah \\
\hline 1. & Pulau Ayer & - & 17.461 & 17.461 \\
\hline 2. & Pulau Bidadari & - & 31.673 & 31.673 \\
\hline 3. & Pulau Kotok Tengah & 1.003 & 1.255 & 2.258 \\
\hline 4. & Pulau Sepa & 844 & 1.682 & 2.526 \\
\hline 5. & Pulau Putri & 1.734 & 104 & 2.774 \\
\hline 6. & Pulau Untung Jawa & - & $\mathbf{6 4 9 . 8 4 6}$ & $\mathbf{6 4 9 . 8 4 6}$ \\
\hline 7. & Pulau Pramuka & $\mathbf{3 . 4 9 4}$ & $\mathbf{1 1 9 . 6 2 6}$ & $\mathbf{1 2 3 . 1 2 3}$ \\
\hline 8. & Pulau Tidung & $\mathbf{3 . 5 7 6}$ & $\mathbf{3 7 0 . 3 1 1}$ & $\mathbf{3 7 3 . 8 8 7}$ \\
\hline 9. & Pulau Harapan & 1.460 & 64.836 & 66.296 \\
\hline 10. & Pulau Kelapa & - & 9.483 & 9.483 \\
\hline 11. & Pulau Pari/Lancang & $\mathbf{3 . 4 1 0}$ & $\mathbf{2 1 5 . 6 2 0}$ & $\mathbf{2 1 9 . 0 3 0}$ \\
\hline 12. & Pulau Macan & - & 116 & 116 \\
\hline & Jumlah & 15.521 & 1.482 .949 & 1.498 .470 \\
\hline
\end{tabular}

Sumber : Dinas Pariwisata dan Kebudayaan Kepulauan Seribu.

Berdasarkan data pada Tabel 1 mengenai jumlah kunjungan wisatawan yang datang ke Kepulauan Seribu pada tahun 2013 yaitu jumlah wisman terbanyak berkunjung ke Pulau Tidung sebanyak 3.576 orang dan Pulau Pramuka sebanyak 3.576 serta Pulau Pari sebanyak 3.410. Berdasarkan hasil survey penelitian pulau tersebut lebih banyak dikunjungi karena pulau tersebut merupakan pulau penduduk yang transportasi, biaya dan fasilitas yang disediakan sudah jauh lebi baik dibandingkan dengan pulau-pulau lainnya.

Pulau Tidung menjadi salah satu destinasi yang diminati banyak pengunjung karena memiliki ciri khas dibandingkan dengan pulau-pulau lainnya yang ada di Kepulauan Seribu. Pulau Tidung memiliki ciri khas pada jembatan cinta, selain jembatan cinta Pulau Tidung juga memiliki beberapa spot untuk melakukan snorkeling dan fasilitas permainan air lainnya seperti banana boat, kano, dll. Tanpa adanya peran 
dari pemerintah dan masyarakat lokal Pulau Tidung tidak akan mungkin dapat berkembang dan menarik perhatian wisatawan untuk berkunjung. Kotler (2009:49) menjelaskan bahwa ciri serta sifat dari suatu produk atau pelayanan akan berpengaruh terhadap kemampuan dalam memuaskan kebutuhan yang dinyatakan atau yang tersirat. Pada usaha jasa diperlukan suatu pelayanan kepada pelanggan yang dapat menyenangkan atau memuaskan pelanggan. Dengan demikian Prabaharan (2008) mengungkapkan bahwa kualitas pelayanan yang baik akan selalu dilihat dan diukur dari sisi konsumen serta pemenuhan kepuasannya pada suatu pelayanan yang diterimanya, sehingga kualitas akan mempengaruhi kesan konsumen terhadap suatu produk atau jasa dan kesan ini akan memberikan dampak pada proses dari kualitas yang diharapkan dan dirasakannya.

Tjiptono (2005) mengatakan bahwa kualitas pelayanan (service quality) dapat diukur dengan menggunakan lima dimensi, yaitu : (1) Reliabilitas (reliability), (2) Daya tanggap (responsiveness), (3) Jaminan/Keyakinan (assurance), (4) Empatu (empathy), (5) Bukti langsung (tangibles). Pada kenyataannya tidak cukup hanya kualitas pelayanan saja yang diberikan oleh peneglola objek wisata tapi mereka juga membutuhkan loyalitas dari wisatawan agar objek wisata yang mereka kelola dapat berkembang, sehingga jika kualitas pelayanan saja yang diberikan tidak akan bisa membuat wisatawan menjadi loyal untuk berkunjung kembali. Oliver (2010) menyebutkan bahwa dari jangka panjang kepuasan akan berdampak pada terbentuknya loyalitas pelanggan.

Loyalitas merupakan kesediaan pelanggan dalam memakai produk perusahaan dalam jangka waktu yang Panjang, bahkan menggunakannya secara ekslusif serta merekomendasikannya kepada orang lain (Lovelock et al, 2010). Sedangkan Artuger et al (2013) mendefinisikan loyalitas adalah mengulangi pembelian, sikap yang positif, komitmen jangka panjang, dan bermaksud untuk melanjutkan afiliansi dan menyebarkan informasi yang positif kepada orang lain.

\section{METODE PENELITIAN}

Artikel ini dibuat berdasarkan variabel yang diteliti maka jenis penelitian terdiri dari penelitian deskriptif. Malhotra (2005:93) menjelaskan bahwa riset desktiptif adalah salah satu jenis riset konklustif yang mempunyai tujuan utama menguraikan sesuatu dan memberikan gambaran hasil penelitian yang biasanya dalam bentuk karakteristik. Tujuan dari penelitian deskriptif adalah membuat deskripsi, gambaran atau lukisan secara sistematis, faktual dan akurat mengenai fakta-fakta, sifat-sifat serta hubungan antar fenomena yang diteliti. Dengan penelitian deskriptif ini, maka dapat diperoleh gambaran mengenai kualitas pelayanan dan loyalitas wisatawan domestik yang berkunjung ke Pulau Tidung Kepulauan Seribu.

Operasional variabel penelitian ini pada variabel kualitas pelayanan diukur dengan menggunakan 5 (lima) dimensi yaitu (1) Tangibles (bukti fisik), (2) Empathy (empati), (3) Responsiveness (ketanggapan), (4) Reliability (kehandalan), dan (5) Assurance (jaminan). Sedangkan untuk loyalitas digunakan 3 (tiga) indikator yaitu (1) pembelian ulang, (2) merekomendasikan kepada orang lain, (3) komitmen merek. Sedangkan untuk populasi pada penelitian ini yaitu wisatawan yang berkunjung ke Pulau Tidung. Untuk jumlah wisatawan yang datang ke Pulau Tidung pada Tahun 2013 berjumlah 3.576 orang. Karena keterbatasan tenaga, biaya, dan waktu yang tersedia, maka penelitian 
dilakukan dengan mengambil sampel sebanyak 100 orang. Metode analisis yang digunakan pada penelitian ini dengan mendeskripsikan tentang kualitas pelayanan dan loyalitas wisatawan yang berkunjung ke Pulau Pari Kepulaua Seribu dengan skala interval dari 1 sampai dengan 5, dengan kriteria penilaian yang dikelompokkan dalam Tabel 2.

Tabel 2 Kriteria Penilaian Mengenai Kualitas Pelayanan dan Loyalitas

\begin{tabular}{|c|c|c|}
\hline \multirow{2}{*}{ Nilai } & \multicolumn{2}{|c|}{ Kriteria Penilaian } \\
\cline { 2 - 3 } & Kualitas Pelayanan & Loyalitas \\
\hline 1 & Sangat Tidak Baik & Sangat Tidak Setuju \\
\hline 2 & Tidak Baik & Tidak Setuju \\
\hline 3 & Cukup Baik & Cukup Setuju \\
\hline 4 & Baik & Setuju \\
\hline 5 & Sangat Baik & Sangat Setuju \\
\hline
\end{tabular}

\section{HASIL DAN PEMBAHASAN}

Pulau Tidung merupakan salah satu kelurahan di kecamatan Kepulauan Seribu Selatan, Kabupaten Kepulauan Seribu, Jakarta. Pulau Tidung terbagi menjadi 2 yaitu Pulau Tidung Besar dan Pulau Tidung Kecil. Pada Pulau Tidung besar dan Pulau Tidung Kecil terdapat jembatan yang menghubungkan dua pulau tersebut. Jembatan tersebut dinamakan jembatan cinta. Jembatan cinta menjadi salah satu daya tarik yang berada di Pulau Tidung ini. Di penghujung jembatan penghubung, menapaki pantai Pulau Tidung Kecil yang merupakan kawasan pengembangbiakan mangrove, masih tampil indah ditelusuri dengan bersepeda, melalui jalan setapak yang dipenuhi dengan ilalang dan pantai sepi yang pasirnya putih lembut, sangat indah pemandangannya.

Selain jembatan cinta yang menjadi daya tarik pada pulau ini terdapat wisata sejarah yaitu adanya makan Raja Pandita yang terletak di ujung barat. Selain wisata sejarah terdapat daya tarik pada wisata bawah laut pada pulau ini. Pesona bawah laut pulau ini dijadikan sebagai refrensi untuk melakuakan snorkeling dan diving oleh wisatawan. Dengan menyewa kapal sekitar Rp 250.000-350.000 wisatawan dapat berkeliling-keliling pulau yang ada di sekitar Pulau Tidung dan kapal tersebut dapat digunakan untuk menuju spot snorkeling dan diving. Dengan mengeluarkan biaya sekitar Rp 35.000 - 50.000 wisatawan dapat menyewa alat-alat selam yang digunakan untuk melihat keindahan bawah laut pulau ini. Untuk penginapan di Pulau Tidung ini pada umumnya berupa Guest House yang dapat dijumpai banyak pada pulau ini. Kisaran harga untuk Guest House berkisar antara Rp 300.000-500.000 dengan fasilitas kamar tidur, kamar mandi dan AC. Jika wisatawan ingin berkeliling-keliling pulau terdapat jasa penyewaan sepeda yang dapat digunakan oleh wisatawan.

Jarak tempuh untuk menuju Pulau Tidung ini kurang lebih 3 jam dari Muara Angke dengan menggunakan kapal penumpang. Pulau Tidung ini menjadi salah satu destinasi favorit wisatawan di Kepulauan Seribu, sehingga banyak paket-paket wisata yang menawarkan perjalannya ke pulau ini. Pada pulau ini terdapat perkampungan warga dan beberapa warung yang menyediakan makan dan minum, selain itu terdapat jalan setapak yang panjang sebagai penghubung untuk menuju fasilitas umum yang ada pada pulau ini seperti kantor polisi, sekolah, dan lain-lain. 
Dari hasil penelitian mengenai kualitas pelayanan dan loyalitas wisatawan Pulau Tidung disajikan pada Tabel 3.

Tabel 3. Kualitas Pelayanan dan Loyalitas Wisatawan Pulau Tidung

\begin{tabular}{|c|c|c|c|}
\hline Item & $\begin{array}{l}\text { Nilai Rata- } \\
\text { Rata }\end{array}$ & Peringkat & Kriteria \\
\hline $\begin{array}{l}\text { Kualitas Pelayanan } \\
\text { Variabel Tangibles (Bukti Fisik) } \\
\text { Kelengkapan Fasilitas (ATM, Toilet, } \\
\text { Homestay, dll) } \\
\text { Kelengkapan perlengkapan olahraga air }\end{array}$ & 3,40 & 9 & $\begin{array}{l}\text { Baik } \\
\text { Baik }\end{array}$ \\
\hline $\begin{array}{l}\text { Variabel Empathy (Empati) } \\
\text { Petugas mengerti keinginan wisatawan } \\
\text { Petugas memberikan perhatian khusus } \\
\text { kepada wisatawan }\end{array}$ & $\begin{array}{l}3,56 \\
3,36\end{array}$ & $\begin{array}{c}4 \\
10\end{array}$ & Baik \\
\hline $\begin{array}{l}\text { Variabel Responsiveness (Daya Tanggap) } \\
\text { Petugas sigap dalam membantu } \\
\text { wisatawan } \\
\text { Petugas sigap dalam memberikan } \\
\text { informasi kepada wisatawan }\end{array}$ & $\begin{array}{l}3,49 \\
3,52\end{array}$ & $\begin{array}{l}7 \\
6\end{array}$ & $\begin{array}{l}\text { Baik } \\
\text { Baik }\end{array}$ \\
\hline $\begin{array}{l}\text { Variabel Reliability (Kehandalan) } \\
\text { Kemampuan petugas dalam } \\
\text { memberikan informasi } \\
\text { Kecepatan petugas dalam memberikan } \\
\text { pelayanan kepada wisatawan }\end{array}$ & $\begin{array}{l}3,59 \\
3,44\end{array}$ & $\begin{array}{l}3 \\
8\end{array}$ & $\begin{array}{l}\text { Baik } \\
\text { Baik }\end{array}$ \\
\hline $\begin{array}{l}\text { Variabel Assurance (Jaminan) } \\
\text { Terjaminnya keamanan dan } \\
\text { kenyamanan wisatawan ketika berada di } \\
\text { Pulau Pari } \\
\text { Pengetahuan petugas dalam } \\
\text { memberikan infromasi yang jelas } \\
\text { kepada wisatawan }\end{array}$ & 3,56 & 5 & $\begin{array}{l}\text { Baik } \\
\text { Baik }\end{array}$ \\
\hline $\begin{array}{l}\text { Loyalitas } \\
\text { Pembelian Ulang } \\
\text { Kesediaan dalam berkunjung kembali } \\
\text { Kesediaan dalam mengalokasikan } \\
\text { anggaran liburan ke Kepualauan Seribu }\end{array}$ & $\begin{array}{l}4,20 \\
3,69\end{array}$ & $\begin{array}{l}1 \\
4\end{array}$ & $\begin{array}{c}\text { Sangat Loyal } \\
\text { Loyal }\end{array}$ \\
\hline $\begin{array}{l}\text { Merekomendasikan Kepada Orang Lain } \\
\text { Kesediaan dalam merekomendasikan } \\
\text { kepada orang lain } \\
\text { Kesediaan dalam menceritakan dan } \\
\text { memberikan informasi kepada orang } \\
\text { lain }\end{array}$ & $\begin{array}{l}3,95 \\
4,10\end{array}$ & $\begin{array}{l}3 \\
2\end{array}$ & $\begin{array}{c}\text { Loyal } \\
\text { Sangat Loyal }\end{array}$ \\
\hline
\end{tabular}




\begin{tabular}{|l|c|c|c|}
\hline \multicolumn{1}{|c|}{ Item } & $\begin{array}{c}\text { Nilai Rata- } \\
\text { Rata }\end{array}$ & Peringkat & Kriteria \\
\hline $\begin{array}{l}\text { Komitmen Merek } \\
\text { Keinginan untuk tidak berpindah ke } \\
\text { objek wisata lain }\end{array}$ & 3,00 & 5 & Loyal \\
\hline
\end{tabular}

Sumber : data hasil olahan kuesioner 2018

Berdasarkan hasil penelitian dari Tabel 3, score nilai rata-rata tertinggi pada kualitas pelayanan terdapat pada variabel Assurance (Jaminan) mengenai pengetahuan petugas dalam memberikan informasi yang jelas kepada wisatawan dengan hasil perolehan nilai rata-rata sebesar 3,66. Menurut wisatawan petugas mampu memberikan informasi dengan jelas ketika wisatawan membutuhkan seperti misalnya menanyakan jam keberangkatan kapal dari Muara Angke menuju Pulau Tidung. Hasil score nilai rata-rata tertinggi kedua yaitu pada variabel Tangibles (Bukti fisik) mengenai kelengkapan perlengkapan olahraga air sebesar 3,63. Di Pulau Pari fasilitas kelengkapan untuk olahraga air sudah cukup lengkap karena disana wisatawan dapat bermain snorkeling, banana boat, donat boat, kano dan fasilitas permainan air lainnya. Hasil score nilai rata-rata terendah pada kualitas pelayanan terdapat pada variabel Empathy (empati) yaitu perhatian khusus yang diberikan oleh petugas masih kurang, namun untuk score rata-rata yang dihasilkan sebesar 3,36 masih masuk ke dalam kategori "Baik".

Untuk tingkat loyalitas wisatawan di Pulau Pari hasil tertinggi pada variabel Pembelian Ulang yaitu mengenai kesediaan wisatawan dalam berkunjung kembali dengan hasil nilai rata-rata sebesar 4,20 dengan kategori "Sangat Loyal". Banyak wisatawan yang tertarik untuk datang kembali ke Pulau Tidung karena menurut mereka Pulau Tidung memberikan keindahan tersendiri untuk pantainya, serta banyaknya fasilitas permainan air yang sudah disediakan oleh pengelola, dengan demikian wisatawan dapat menikmati fasilitas permainan tersebut berasama keluarga atau teman. Untuk hasil score loyalitas terendah pada variabel Komitmen merek mengenai keinginan untuk tidak berpindah ke objek wisata lain dengan score nilai rata-rata sebesar 3,00 namun masih masuk ke dalam kategori "Loyal". Wisatawan yang datang masih ingin berkunjung ke objek wisata lainnya seperti pulau-pulau lainnya yang ada di Kepulauan Seribu karena mereka ingin merasakan keindahan-keindangan pada pulau lainnya.

\section{KESIMPULAN}

Kesimpulan dari penelitian ini sebagai berikut: (1) Kualitas pelayanan di Pulau Tidung hasil tertinggi yaitu mengenai pengetahuan petugas dalam memberikan informasi yang jelas kepada wisatwan dengan nilai rata-rata 3,62 dengan kriteria baik, sedangkan untuk hasil terendah pada perhatian khusus yang diberikan petugas kepada wisatawan dengan hasil nilai rata-rata sebesar 3,36 dalam kriteria baik dan (2) untuk loyalitas wisatawan yang berkunjung ke Pulau Tidung dengan hasil tertinggi pada kesediaan wisatawan dalam berkunjung kembali dengan perolehan nilai rata-rata sebesar 4,16 dengan kriteria sangat loyal dan untuk hasil penilaian terendah pada keinginan untuk tidak berpindah ke objek wisata lain dengan hasil nilai rata-rata sebesar 3,03 dengan kriteria Loyal. 
Dengan adanya penelitian ini diharapkan ada perhatian yang lebih baik dari pemerintah dan pengelola objek wisata mengenai kualitas pelayanan yang diberikan kepada wisatawan agar tercapainya kulitas pelayanan yang jauh lebih baik lagi, selain itu petugas mampu memberikan perhatian khusus kepada wisatawan agar wistawan merasa diperhatikan oleh petugas baik dari segi keamanan serta keselamatan atau informasi yang dibutuhkan oleh wisatawan selama berada di Pulau Tidung. Untuk menumbuhkan rasa loyalitas yang lebih kepada wisatawan petugas harus mampu untuk lebih memperhatikan apa saja yang dibutuhkan oleh wisatawan selama berada di Pulau Tidung agar wistawan tertarik untuk berkunjung kembali ke Pulau Tidung serta memberikan ciri khas tersendiri pada Pulau Tidung.

\section{DAFTAR PUSTAKA}

Kotler, P. (2009). Manajemen Pemasaran. Jakarta : Erlangga

Lovelock, Christopher H \& Lauren K. Wright. (2010). Manajemen Pemasaran Jasa. Jakarta : PT Indeks

Malhotra. (2005). Riset Pemasaran. Jilid I, Edisi 4. Jakarta : Indeks Kelompok Gramedia

Oliver, R, L. (2010). “Whence Customer Loyalty”Journal of Marketing, Vol 63.

Prabaharan, B., A. Arulraj, V. Rajagopal. (2008). Service Quality on Tourism: Application of Structural Equation Modelling, Conference on Tourism in India Challenges Ahead.

Tjiptono, F. (2005). Pemasaran Jasa. Edisi Pertama, Yogyakarta: Penerbit Bayumedia Publishing.

Undang-Undang Nomor 10 Tahun 2009 Tentang Kepariwisataan 